Zhao, O., Gardner, L., \& Young, B. (2016). Testing and numerical modelling of austenitic stainless steel CHS beam-columns. Engineering Structures, 111, 263-274.

\title{
Testing and numerical modelling of austenitic stainless steel CHS beam-
}

\section{columns}

\author{
Ou Zhao ${ }^{* a}$, Leroy Gardner ${ }^{b}$, Ben Young ${ }^{\mathrm{c}}$ \\ ${ }^{\mathrm{a}, \mathrm{b}}$ Dept. of Civil and Environmental Engineering, Imperial College London, London, UK \\ ${ }^{c}$ Dept. of Civil Engineering, The University of Hong Kong, Pokfulam Road, Hong Kong, China \\ * Corresponding author, Phone: +44 (0)20 75946058 \\ Email: ou.zhao11@imperial.ac.uk
}

\begin{abstract}
This paper presents a comprehensive experimental and numerical study of the global stability of stainless steel circular hollow section (CHS) structural members subjected to combined axial load and bending moment. The experimental investigation, which was carried out on two grade 1.4301 austenitic stainless steel cross-section sizes (CHS $60.5 \times 2.8$ and CHS $76.3 \times 3$ ), included material coupon tests, initial geometric measurements, two column tests, and ten beam-column tests. The test results were employed in a parallel numerical simulation programme for the validation of finite element (FE) models, by means of which a series of parametric studies were carried out to extend the available results over a wider range of cross-section sizes, member lengths and loading combinations. The experimentally and numerically derived data were used to assess the structural performance of CHS beamcolumns and to determine the accuracy of the current design provisions given in the European code, American specification, Australian/New Zealand standard, and other recent proposed approaches. Generally, all the existing design methods were shown to yield a high degree of
\end{abstract}


scatter in the prediction of beam-column strength, with both conservative and over-predicted capacities. The scatter was attributed mainly to inaccurate predictions of the column buckling and bending end points of the design beam-column interaction curves (i.e. member strengths under pure compression and pure bending, respectively) and inaccurate interaction factors. The development of improved provisions for the design of stainless steel circular hollow section beam-columns is currently underway.

\section{Introduction}

Cold-formed stainless steel circular hollow sections are being increasingly used in a range of civil and offshore engineering applications, due to the unique combination of the durability, high strength, and ductility of the material, coupled with the equal structural performance about all axes, low drag coefficients when exposed to wind or fluid, high torsional resistance and potential for concrete infilling of circular hollow profiles. Previous experimental and numerical studies into the behaviour and design of circular hollow section structural members have been carried out, aiming at verifying their performance under varying loading conditions, assessing the efficiency of the established design codes, and developing more economic design approaches. A series of stub column [1-10] and bending $[3,11,12]$ tests have been performed on CHS of varying cross-section classes, in order to investigate their local buckling behaviour and the corresponding loading-carrying and deformation capacities under isolated loading conditions. Zhao et al. [13] conducted a comprehensive experimental programme on eccentrically loaded stub columns to study the structural performance of stainless steel CHS subjected to combined axial load and bending moment. Comparisons of the test results with codified cross-section strength predictions revealed undue conservatism in current design standards, mainly due to the lack of consideration of the pronounced strain 
hardening exhibited by stainless steels. To address this shortcoming, Buchanan et al. [14] and Zhao et al. [15] extended the application of the deformation-based continuous strength method (CSM) [16-20] to circular hollow sections, which allows a rational exploitation of strain hardening in the determination of the cross-section resistances of stainless steel CHS under isolated and combined loading conditions, and thus results in substantially improved strength predictions. Gardner et al. [21] also proposed revised slenderness limits for the classification of circular hollow sections, leading to improved capacity predictions than the codified limits, compared to previous limits. Although comprehensive research has been conducted on the local buckling behaviour of CHS, research into the member stability remains relatively scarce, despite some previous study on columns [1-3] and beam-columns [2,3]. The structural performance of CHS members requires further investigation and this is therefore the subject of the present study.

In the present paper, a test programme on circular hollow section structural members subjected to pure compression and combined axial load and bending moment was firstly carried out. This was followed by a numerical modelling programme, in which finite element (FE) models were initially developed to replicate the experimental results and then used to conduct parametric studies to generate further structural performance data over a range of cross-section and member slendernesses, and combinations of loading. The numerical results were analysed with the experimental data to develop a comprehensive understanding of the global buckling behaviour of stainless steel CHS beam-columns. Finally, the accuracy of existing methods for the stability design of CHS members, as given in the European code EN 1993-1-4 [22], American specification SEI/ASCE-8 [23], Australian/New Zealand standard AS/NZS 4673 [24], and the proposals by Greiner and Kettler [25], was evaluated through comparisons of the test and FE results with the corresponding predicted strengths. 


\section{Experimental investigation}

\subsection{General}

An experimental programme was carried out in order to study the combined in-plane bending and flexural buckling behaviour of stainless steel circular hollow section beam-columns. The two studied cross-sections were CHS $60.5 \times 2.8$ and CHS $76.3 \times 3$, which were cold-formed and seam-welded from grade EN 1.4301 austenitic stainless steel. Both of the cross-sections are Class 1, according to the slenderness limits set out in EN 1993-1-4 [22]. For each crosssection, one column test and five beam-column tests were conducted. The employed experimental setup and procedures, as well as the key obtained test results, load-deformation histories and failure modes are fully reported in this section.

\subsection{Material testing and geometric imperfection measurements}

The material properties of the tested cross-sections were determined through prior tensile coupon testing [13] and a brief summary of the key test results are reported herein. For each of the two studied cross-sections, two longitudinal coupons, extracted at 90 degrees from the weld (see Fig. 1), were tested to determine the basic material stress-strain response of the austenitic stainless steel circular hollow section members. The key results are reported in Table 1, where $E$ is the Young's modulus, $\sigma_{0.2}$ is the $0.2 \%$ proof stress, $\sigma_{1.0}$ is the $1.0 \%$ proof stress, $\sigma_{u}$ is the ultimate tensile strength, $\varepsilon_{u}$ is the strain at the ultimate tensile stress, $\varepsilon_{f}$ is the plastic strain at fracture measured over the standard gauge length of $25 \mathrm{~mm}$, and $n, n_{0.2,1.0}^{\prime}$ and $n_{0.2, u}^{\prime}$ are the strain hardening exponents used in the two-stage Ramberg-Osgood (R-O) material model [26-30]. 
Initial global imperfections influence the load-lateral deflection response and ultimate loadcarrying capacity of compression members. Thus, prior to structural testing, initial global geometric imperfection amplitudes $\omega_{g}$ of the column and beam-column specimens in the direction of buckling were measured using a theodolite, based on the measurements taken at mid-height and near the two ends of the specimens.

\subsection{Column and beam-column tests}

All twelve test specimens (two columns and ten beam-columns) had a fixed nominal length of $1450 \mathrm{~mm}$, while the nominal initial loading eccentricities were varied to provide a range of bending moment-to-axial load ratios, resulting in different combinations of loading being examined. Measurements of the geometric dimensions and initial global imperfection amplitudes of the specimens were conducted before $25.4 \mathrm{~mm}$ thick end plates were welded to the specimen ends. The member tests were conducted using an AVERY $1000 \mathrm{kN}$ hydraulic testing machine with pin-ended bearings at both ends, at a constant speed of $0.2 \mathrm{~mm} / \mathrm{min}$. Each pin-ended bearing was made up of a wedge plate containing a knife-edge wedge, and a pit plate with a V-shaped groove, as shown in Figs 2(a) and 2(b). The specimens were bolted to the wedge plates, which had slotted holes to allow adjustment of the relative position between the centrelines of the specimen and the knife-edge to achieve the required loading eccentricities, before being placed in the testing machine between the two pit plates. The top pit plate was connected to a rigid end platten of the test machine, while the bottom pit plate was seated on a special bearing, which was initially free to rotate in any direction. A small alignment load of $2 \mathrm{kN}$ was then applied, at which point the special bearing was restrained against twisting and rotation by tightening the vertical and horizontal bolts. This procedure ensures full contact between the knife-edges and V-grooved pit plates. Figs 2(a) and 2(b) 
show a photograph and schematic diagram of the beam-column experimental setup, consisting of one LVDT located at the mid-height of the specimens to measure the lateral deflection, three LVDTs placed at one end of the specimens to determine the corresponding end rotation and shortening, and two strain gauges attached to the extreme fibres of the section at mid-height to capture the longitudinal strains at the maximum compressive fibre and the maximum tensile (or the minimum compressive, in some cases) fibre. The strain gauge values were employed to determine the actual initial loading eccentricities, according to Eq. (1) [31,32], in which $I$ is the second moment of area, $\varepsilon_{\max }$ and $\varepsilon_{\min }$ are the strain gauge values at the maximum compressive fibre and the maximum tensile (or the minimum compressive, in some cases) fibre, respectively, $\Delta$ is the lateral deflection at mid-height, $\omega_{g}$ is the initial global imperfection at mid-height and $N$ is the applied load. Note that these determined eccentricities are employed in the numerical modelling in Section 3 and the design calculations in Section 4.

$$
e_{0}=\frac{E I\left(\varepsilon_{\max }-\varepsilon_{\min }\right)}{D N}-\Delta-\omega_{g}
$$

The measured geometric properties and initial global imperfection amplitude for each specimen are reported in Table 2, in which $L$ is the specimen length, $L_{e}$ is the effective member length (measured between the knife-edges), $D$ is the outer cross-section diameter, $t$ is the cross-section thickness, $A$ is the cross-section area, $\bar{\lambda}=\sqrt{A \sigma_{0.2} / N_{c r}}$ is the member nondimensional slenderness, where $N_{c r}=\pi^{2} E I / L_{e}{ }^{2}$ is the Euler buckling load about the buckling axis, and $\omega_{g}$ is the measured global imperfection amplitude. Note that the term 'nondimensional slenderness' is that employed in the Eurocode, but this will be referred to as 'relative slenderness' in the remainder of this paper. Table 3 summarises the key obtained test results, including the initial nominal loading eccentricity $e_{n}$, the initial calculated (actual) 
loading eccentricity from the strain gauges $e_{0}$, the ultimate load $N_{u}$, the mid-height lateral deflection at the ultimate load $\delta_{u}$, the end rotation at failure $\phi_{u}$, and the corresponding firstorder elastic, second-order elastic and second-order inelastic bending moments at the ultimate load ( $M_{1 s t, e l, u}, M_{2 n d, e l, u}$, and $M_{2 n d, i n e l, u}$, respectively), which were calculated from Eqs (2)-(4) [33], respectively,

$$
\begin{aligned}
& M_{1 s t, e l, u}=N_{u}\left(e_{0}+\omega_{g}\right) \\
& M_{2 n d, e l, u}=M_{1 s t, e l, u} /\left(1-N_{u} / N_{c r}\right) \\
& M_{2 n d, \text { inel }, u}=N_{u}\left(e_{0}+\omega_{g}+\delta_{u}\right)
\end{aligned}
$$

The full experimental load-deformation histories are shown, in terms of the load-mid-height lateral deflection curves, in Figs 3 and 4 for the CHS $60.5 \times 2.8$ and CHS $76.3 \times 3$ specimens, respectively, while typical failure modes are displayed in Figs 5 and 6, exhibiting combined in-plane bending and flexural buckling without any visible signs of local buckling.

\section{Numerical modelling}

\subsection{General}

In conjunction with the experimental study, a numerical modelling programme, using the general-purpose finite element analysis package ABAQUS [34], was carried out. The FE models were firstly validated against the reported experimental results and then used to conduct parametric studies to expand the current data pool over a wider range of crosssection sizes, member relative slendernesses, and combinations of loading. 


\subsection{Basic modelling assumptions}

The four-noded doubly curved shell element with reduced integration and finite membrane strain, S4R [34], having been used successfully in previous numerical studies of thin-walled structures [35-42], was selected as the element type throughout the present numerical simulations. The assigned mesh size along the circumferential and longitudinal directions of the sections was equal to the cross-section thickness. Since the experimental failure modes of the CHS columns and beam-columns displayed symmetry with respect to the mid-height plane and the plane perpendicular to the buckling axis, only half of the cross-section and member length were modelled, enabling significant savings in computational time. The measured engineering material stress-strain responses, represented by the two-stage Ramberg-Osgood material model [26-30], were converted into the format of true stress and log plastic strain according to Eq. (5) and Eq. (6), for input into ABAQUS, where $\sigma_{\text {true }}$ is the true tress, $\varepsilon_{l n}^{p l}$ is the logarithmic plastic strain, and $\sigma_{\text {nom }}$ and $\varepsilon_{n o m}$ are the engineering stress and strain, respectively. Residual stresses were not explicitly incorporated into the modelled sections, principally due to the negligible influence of membrane residual stresses on coldformed stainless steel tubular profiles and the inherent presence of the more dominant through-thickness residual stresses into the measured material properties [43-45]. With regards to end section boundary conditions, all degrees of freedom for the nodes of the loaded end were coupled to an eccentric reference point, which only allowed longitudinal translation and rotation about the axis of buckling, in order to simulate pin-ended boundary conditions. The eccentricity was set equal to the corresponding value used in the beam-column tests. In addition, the eccentric reference point was offset longitudinally from the loaded end section by $87.4 \mathrm{~mm}$ (i.e. the distance from the knife-edge to the specimen end), in accordance with the actual knife-edge arrangement and dimensions used in the tests. 


$$
\begin{aligned}
& \sigma_{\text {true }}=\sigma_{\text {nom }}\left(1+\varepsilon_{\text {nom }}\right) \\
& \varepsilon_{l n}^{p l}=\ln \left(1+\varepsilon_{\text {nom }}\right)-\frac{\sigma_{\text {true }}}{E}
\end{aligned}
$$

Initial local and global geometric imperfections were incorporated into the developed FE models in the form of the respective lowest elastic buckling mode shapes under the applied loading conditions; these shapes generally represent the most unfavourable imperfection patterns, and may be determined by a prior eigenvalue buckling analysis [34]. Three global and two local imperfection amplitudes were employed in a sensitivity study, leading to six imperfection combinations being considered. The two adopted local imperfection values were equal to $1 / 10$ and $1 / 100$ of the cross-section thickness, while the three considered global imperfection amplitudes were the measured value $\omega_{g}$, and two fractions of the effective member length $\left(L_{e} / 1000\right.$ and $\left.L_{e} / 1500\right)$. Upon incorporation of the initial geometric imperfections into the finite element models, geometrically and materially nonlinear analyses were conducted, using the modified Riks solution method [34], to trace the full loaddeformation histories of the models.

\subsection{Validation of numerical models}

The accuracy of the developed circular hollow section beam-column FE models was assessed through comparisons of the derived ultimate loads, load-deformation curves and failure modes with those from the corresponding experiments. Table 4 reports the ratios of numerical to experimental failure loads for the various imperfection combinations; the results indicate that the test failure loads are generally well predicted for all six considered combinations of local and global imperfection amplitudes. Use of the measured global imperfections led to the least scattered predictions, but the best average agreement was obtained when the global 
imperfection of $L_{e} / 1000$ and local imperfection of $t / 10$ was employed. Typical experimental load-mid-height lateral deflection curves are compared with their numerical counterparts in Figs 7 and 8, showing that the full experimental load-deformation histories are accurately replicated. Comparisons between the typical test and FE failure modes also indicate excellent agreement, as depicted in Figs 5 and 6. Overall, it may be concluded that the developed numerical models are capable of accurately simulating the behaviour shown in the circular hollow section beam-column tests, and are thus suitable for conducting parametric studies.

\subsection{Parametric studies}

Upon validation of the FE models against the test results, a series of parametric studies were performed to generate further beam-column data over a wider range of cross-section sizes, member relative slendernesses, and combinations of loading. In the parametric studies, the measured material properties of the CHS $60.5 \times 2.8$ test specimens were adopted, while the initial local and global imperfection amplitudes were taken as 1/10 of the cross-section thickness and 1/1000 of the effective member length, respectively. Note that the considered local geometric imperfection amplitudes are fixed proportions of the cross-section thickness, which are considered adequate for the structural sections examined in this study, which do not exhibit high sensitivity to imperfections; it is however recognised that for thinner and larger shells, a more rigorous treatment of imperfections may be necessary [46]. The outer diameter of the modelled cross-sections ranged from $40 \mathrm{~mm}$ to $150 \mathrm{~mm}$, with the thickness varying between $0.8 \mathrm{~mm}$ and $15 \mathrm{~mm}$, which resulted in the ratio of $D / t \varepsilon^{2}$ between 13 to 89 , covering Class 1, 2 and 3 cross-sections, according to the slenderness limits in EN 1993-1-4 [22], where $\varepsilon$ is a material parameter defined as $\sqrt{\left(235 / \sigma_{0.2}\right)(E / 210000)}$. The bucking lengths of the beam-column FE models were varied to cover a wide spectrum of member 
slenderness $\bar{\lambda}$ between 0.43 and 3.03. The employed initial loading eccentricities, ranging from $0 \mathrm{~mm}$ to $600 \mathrm{~mm}$, provided a broad range of proportions of axial load to bending moment. In total, 285 parametric study results were generated, including 150 for Class 1 or 2 cross-sections and 135 for Class 3 cross-sections.

\section{Discussion and assessment of current design methods}

\subsection{General}

In this section, four existing design approaches for stainless steel circular hollow section beam-columns, including three codified methods: the European code EN 1993-1-4 [22], American specification SEI/ASCE-8 [23], Australian/New Zealand standard AS/NZS 4673 [24] and a recent proposal by Greiner and Kettler [25], are described and assessed. The accuracy of each approach is evaluated through comparisons of the experimental and numerical failure loads with the predicted failure loads $N_{u} / N_{u \text {,pred, }}$, as reported in Tables 5 and 6 for Class 1 or 2 and Class 3 cross-sections, respectively, where $N_{u}$ is the ultimate test (or FE) axial load corresponding to the distance on the $\mathrm{N}-\mathrm{M}$ interaction curve from the origin to the test (or FE) data point (see Fig. 9), while $N_{u \text {,pred }}$ is the predicted axial load corresponding to the distance from the origin to the intersection with the design interaction curve, assuming proportional loading $[15,47]$. A value of $N_{u} / N_{u, p r e d}$ greater than unity indicates that the test (or FE) data point lies on the safe side of the design interaction curve. Note that the measured material and geometric properties have been used in all comparisons and that all partial safety factors have been set equal to unity. 


\subsection{European code EN 1993-1-4 (EC3)}

The current European code EN 1993-1-4 [22] for stainless steel adopts the general format of the beam-column interaction formulae used in EN 1993-1-1 [48] for carbon steel, but with modified interaction buckling factors to consider the effects of the rounded stress-strain response of stainless steel on member instability. The design beam-column interaction formula is given by Eq. (7), in which $N_{E d}$ is the design axial load, $M_{E d}=N_{E d} e_{0}$ is the design maximum first order bending moment about the axis of buckling, $N_{b, R d}$ is the column buckling strength, calculated in accordance with Clause 5.4.2 of EN 1993-1-4 for uniform members in compression, $e_{N}$ is the shift in the neutral axis when the cross-section is subjected to uniform compression, and is equal to zero for doubly symmetric cross-sections, $W_{p l}$ is the plastic section modulus about the buckling axis, $\beta_{W}$ is a parameter which is equal to unity for Class 1 or 2 sections, the ratio of elastic to plastic moduli for Class 3 sections and the ratio of effective to plastic moduli for Class 4 cross-sections, and $k$ is the interaction factor, as defined by Eq. (8), in which the lower limit of 1.2 prevents over-predictions of beam-column strengths for Class 1 or 2 cross-sections.

$$
\begin{aligned}
& \frac{N_{E d}}{N_{b, R d}}+k\left(\frac{M_{E d}+N_{E d} e_{N}}{\beta_{W} W_{p l} \sigma_{0.2}}\right) \leq 1 \\
& 1.2 \leq k=1+2(\bar{\lambda}-0.5) \frac{N_{E d}}{N_{b, R d}} \leq 1.2+2 \frac{N_{E d}}{N_{b, R d}}
\end{aligned}
$$

The experimental and numerical results are compared with the Eurocode capacity predictions in Fig. 10, where the test (or FE) to EC3 predicted failure load ratio $N_{u} / N_{u, E C 3}$ is plotted against the angle parameter $\theta$, which is defined by Eq. (9) and illustrated in Fig. 11, where $N_{R}$ and $M_{R}$ are the codified column buckling strength and bending moment capacity, respectively. Note that $\theta=0^{\circ}$ represents pure bending while $\theta=90^{\circ}$ corresponds to pure compression. The 
comparisons generally reveal a transition from slightly unsafe predictions of design column buckling loads to unduly conservative elastic or plastic moment resistances, as the applied loading varies from pure compression to pure bending (i.e. $\theta$ moves from $90^{\circ}$ to $0^{\circ}$ ).

$\theta=\tan ^{-1}\left[\left(N_{E d} / N_{R}\right) /\left(M_{E d} / M_{R}\right)\right]$

A numerical evaluation of the European code EN 1993-1-4 [22] is reported in Tables 5 and 6, showing that the mean test (or FE) to EC3 predicted capacity ratios $N_{u} / N_{u, E C 3}$ are equal to 1.06 with a coefficient of the variation (COV) equal to 0.06 , and 1.20 with a $\mathrm{COV}$ of 0.11 for beam-columns of Class 1 or 2 and Class 3 cross-sections, respectively. The results indicate that the European code yields relatively accurate design beam-column strengths for Class 1 or 2 circular hollow sections, but leads to unduly conservative and scattered capacity predictions for Class 3 cross-sections. The conservatism and scatter can be mainly attributed to the inaccurate prediction of the bending end point of the interaction curve (i.e. cross-section moment capacity under pure bending), which suffer from being determined without accounting for strain hardening, and the interaction factors, which generally underestimate the beneficial plasticity effects in the interaction.

\subsection{American Specification SEI/ASCE-8}

The beam-column interaction buckling formulae in the American specification SEI/ASCE-8 [23] were derived on the basis of second-order elastic theory, as given by Eq. (10), where $N_{n}$ is the column buckling strength, which is determined using the tangent modulus approach according to Clause 3.4.1 of SEI/ASCE-8, $M_{n}$ is the bending moment capacity, calculated from Eq. (11), where $K_{c}$ is the strength reduction factor for slender cross-sections, defined by Eq. (12), in which $C$ is the ratio of material effective proportional limit to yield strength, and 
$\lambda_{c}$ is equal to $3.084 C, C_{m}$ is the equivalent moment factor, which is equal to unity for a beam-column with constant first order bending moment along the member length, and $\alpha_{n}$ is the magnification factor considering the induced second-order bending moment, defined as $\left(1-N_{E d} / N_{c r}\right)$. Note that the American specification applies to cylindrical tubular sections with the outer diameter to thickness ratio $D / t$ of less than $0.881 E / \sigma_{0.2}$, and limits the maximum attainable bending capacity to the elastic moment $M_{e l}$ for all four classes of cross-section.

$$
\begin{aligned}
& \frac{N_{E d}}{N_{n}}+\frac{C_{m} M_{E d}}{M_{n} \alpha_{n}} \leq 1 \\
& M_{n}= \begin{cases}M_{e l} & \text { for } \begin{array}{l}
D / t<0.112 E / \sigma_{0.2} \\
K_{c} M_{e l}
\end{array} \\
0.112 E / \sigma_{0.2} \leq D / t \leq 0.881 E / \sigma_{0.2}\end{cases} \\
& K_{c}=\frac{(1-C)\left(E / \sigma_{0.2}\right)}{\left(8.93-\lambda_{c}\right)(D / t)}+\frac{5.882 C}{8.93-\lambda_{c}} \leq 1
\end{aligned}
$$

Fig.12 presents comparisons between the test (or FE) ultimate capacities and SEI/ASCE-8 predicted capacities; the comparisons show that the tangent modulus approach adopted in the American specification generally over-predicts the column buckling strength, while the use of the elastic moment capacity significantly underestimates the cross-section bending strength. Thus, similarly to the European code EN 1993-1-4 [22], the American specification SEI/ASCE-8 [23] generally results in unduly conservative capacity predictions for beamcolumns where bending moments are dominant, but leads to unsafe strength predictions for beam-column structural members with large axial forces. The mean ratios of test (or FE) to ASCE predicted beam-column capacities, as reported in Tables 5 and 6 , are equal respectively to 1.09 and 1.08 for Class 1 or 2 and Class 3 cross-sections, respectively, with corresponding COVs equal to 0.13 and 0.10 , revealing acceptable accuracy on average, but with a high degree of scatter and many unsafe predictions. 


\subsection{Australian/New Zealand standard AS/NZS 4673}

The Australian/New Zealand standard AS/NZS 4673 [24] employs the same design beamcolumn interaction formulae as those used in the American specification, as shown in Eq. (13). However, there are differences in the determination of column buckling strength $N_{a}$ and bending moment capacity $M_{a}$. Two alternative methods are given in Clause 3.4 .2 of AS/NZS 4673 [24] for the calculation of stainless steel column buckling resistance: (a) the tangent modulus approach, as used in SEI/ASCE-8 [23], and (b) the explicit method [49], which was developed based on the Perry-Robertson buckling formulation with a series of imperfection parameters for different stainless steel grades. Both methods are evaluated herein. For the calculation of bending resistance, Clause 3.6.2 of AS/NZS 4673 [24] allows use of the full plastic moment capacity $M_{p l}$ for cross-sections with $D / t$ ratios less than $0.078 E / \sigma_{0.2}$, the elastic moment capacity $M_{e l}$ for sections with $D / t$ ratios greater than $0.078 E / \sigma_{0.2}$ but less than $0.31 E / \sigma_{0.2}$, and a reduced elastic moment capacity $K_{a} M_{e l}$ for slender cross-sections with $D / t$ ratios greater than $0.31 E / \sigma_{0.2}$, as given by Eq. (14), where $K_{a}$ is the AS/NZS strength reduction factor for local buckling, determined from Eq. (15).

$$
\begin{aligned}
& \frac{N_{E d}}{N_{a}}+\frac{C_{m} M_{E d}}{M_{a} \alpha_{n}} \leq 1 \\
& M_{a}=\left\{\begin{array}{lr}
M_{p l} & D / t<0.078 E / \sigma_{0.2} \\
M_{e l} & \text { for } \quad 0.078 E / \sigma_{0.2} \leq D / t<0.31 E / \sigma_{0.2} \\
K_{a} M_{e l} & 0.31 E / \sigma_{0.2} \leq D / t \leq 0.881 E / \sigma_{0.2}
\end{array}\right. \\
& K_{a}=\frac{(1-C)\left(E / \sigma_{0.2}\right)}{\left(3.226-\lambda_{c}\right)(D / t)}+\frac{0.178 C}{3.226-\lambda_{c}} \leq 1
\end{aligned}
$$

The accuracy of AS/NZS 4673 [24] is assessed by comparing the experimental and numerical failure loads with the predicted failure loads, as shown in Tables 5 and 6 and Figs 13 and 14, 
where $N_{u} / N_{u, A S / N Z S-T}$ signifies the ratio of test (or FE) failure load to predicted failure load determined on the basis of the tangent modulus approach for column buckling, while $N_{u} / N_{u, A S / N Z S-E}$ indicates the same ratio but with the calculation of column buckling strengths made based on the explicit method. The comparisons show that the explicit approach results in safe column buckling strength predictions, in contrast to the generally unsafe predictions that derived from the tangent modulus approach and the Eurocode. However, as shown in Fig. 13, even with the use of the safely predicted column buckling loads and plastic moment capacities as the end points, the AS/NZS interaction formula still leads to a number of unsafe strength predictions for beam-columns of Class 1 or 2 cross-sections, particularly for intermediate and high levels of bending moment. This suggests slightly optimistic codified interaction factors. Note that the American specification employs the same set of interaction factors and thus may also suffer from over-predictions of the interaction between the axial force and bending moment, through this effect was less evident in the earlier comparisons (Fig. 12) due to the use of the unduly conservative elastic moment capacity as the end point of the design curve. Overall, the mean ratio of the test (or FE) to predicted failure load $N_{u} / N_{u, A S / N Z S-E}$ is equal to 1.06 for Class 1 and 2 sections and 1.18 for Class 3 sections, both with COVs of 0.06. Similar observations emerge from Fig. 14, though in this case, the number of unsafe predictions is significant greater due to the over-predicted column buckling resistances arising from the tangent modulus approach. For beam-columns of Class 1 or 2 cross-sections, the Australian/New Zealand standard with the tangent modulus approach for column buckling leads to unsafe strength predictions with the mean value of $N_{u} / N_{u, A S / N Z S-T}$ ratio equal to 0.95 and the $\mathrm{COV}$ equal to 0.07 , while for Class 3 cross-sections, the mean $N_{u} / N_{u, A S / N Z S-T}$ ratio is equal to the value from the American specification. 


\subsection{Greiner and Kettler's method}

Greiner and Kettler [25] proposed new interaction buckling factors for stainless steel beamcolumns of Class 1 or 2 cross-sections through numerical simulations of pin-ended members in the relative slenderness range between 0.3 and 3.0, and on the basis of the traditional derivation procedures and the general format of the Eurocode beam-column formulae for carbon steel. The beam-column design formula and the proposed interaction factor $k_{G \& K}$ are given by Eqs (16) and (17), respectively. Note that the proposals only apply to Class 1 and 2 circular hollow sections, while investigations into beam-columns of Class 3 and 4 sections have not yet been reported.

$$
\begin{aligned}
& \frac{N_{E d}}{N_{b, R d}}+k_{G \& K} \frac{M_{E d}}{W_{p l} \sigma_{0.2}} \leq 1 \\
& k_{G \& K}=0.9+2.2\left(\frac{N_{E d}}{N_{b, R d}}\right)(\bar{\lambda}-0.4) \leq 0.9+2.42\left(\frac{N_{E d}}{N_{b, R d}}\right)
\end{aligned}
$$

The accuracy of Greiner and Kettler's proposals for the design of stainless steel circular hollow section beam-columns is evaluated herein through comparisons of the experimental and numerical results with the predicted capacities. The comparisons, reported in Table 5, show a high level of accuracy with the mean ratio of $N_{u} / N_{u, G \& K}$ equal to 1.04 and the corresponding $\mathrm{COV}$ equal to 0.06 . However, many of the beam-column capacity predictions, as indicated in Fig. 15, are on the unsafe side. This observation is in line with similar findings from a previous study [47] on square and rectangular hollow section beam-columns, which showed that Greiner and Kettler's method gave accurate strength predictions on average, but with many results on the unsafe side. 


\subsection{Overall comparisons and summary}

Figs 16 and 17 depict comparisons of the beam-column test results against the design interaction curves obtained from the five aforementioned methods for the CHS $60.5 \times 2.8$ and CHS $76.3 \times 3$ specimens, respectively. Overall, considering both the test and FE results, the findings of the comparisons may be summarised as follows. The European code yields relatively accurate strength predictions for stainless steel beam-columns with Class 1 or 2 cross-sections but unduly conservative beam-column resistances in the case of Class 3 sections; inaccuracies arise due to the lack of consideration of strain hardening in the determination of the bending end point of the EC3 design curve and the use of conservative interaction factors. The American specification leads to greatly over-predicted strengths for beam-columns under large axial forces but yields very conservative capacity predictions for beam-columns subjected to high bending moments due to the assignment of the elastic moment capacity to cross-sections of all classes. The two Australian/New Zealand methods generally overestimate the interaction effects between axial load and bending moment, and thus result in many unsafe predictions, especially for Class 1 or 2 cross-sections. Although Greiner and Kettler's method was shown to offer the best representation of the beam-column test and FE results, it also led to many unsafe predictions. Overall, all the existing design approaches exhibit some weakness, and hence the development of safe, accurate and reliable design rules is underway as part of a wider study.

\section{Conclusions}

A comprehensive experimental and numerical investigation of stainless steel CHS beamcolumns has been conducted to study their combined in-plane bending and flexural buckling 
behaviour under combined axial load plus bending. The experimental programme comprised material tensile coupon tests, imperfection measurements, two column tests and ten beamcolumn tests, of which the key results, load-mid-height lateral deflection curves and failure modes were fully reported. The obtained test results were employed in a parallel numerical modelling programme for the validation of finite element models, which were then used in a series of parametric studies to generate further structural performance data over a range of cross-section and member slendernesses, and loading combinations. The derived test and FE results were employed to assess the suitability of the current established beam-column design rules given in the European code EN 1993-1-4 [22], American specification SEI/ASCE-8 [23], Australia and New Zealand standard AS/NZS 4673 [24] and the proposal of Greiner and Kettler [25]. Generally, all the existing design methods had some identifiable shortcomings, leading to both unduly conservative and unsafe beam-column capacity predictions; problems principally stemmed from inaccurate column buckling and bending end points, and interaction factors that did not fully capture the response of the stainless steel members under combined loading. Therefore, it is concluded that improvement in the design of austenitic stainless steel circular hollow section beam-columns is required, and hence further research is underway in this area.

\section{Acknowledgements}

The authors would like to thank the Joint PhD Scholarship Programme from Imperial College London for its financial support and Mr Man Lai Wong from the University of Hong Kong for his assistance during the experimental investigations. 


\section{References}

[1] Rasmussen KJR, Hancock GJ. Design of cold-formed stainless steel tubular members. I: Columns. Journal of Structural Engineering (ASCE), 1993;119(8):2349-67.

[2] Talja, A. Test report on welded I and CHS beams, columns and beam-columns. Report to ECSC. VTT Building Technology, Finland; 1997.

[3] Burgan BA, Baddoo NR, Gilsenan KA. Structural design of stainless steel members comparison between Eurocode 3, Part 1.4 and test results. Journal of Constructional Steel Research, 2000;54(1):51-73.

[4] Young B, Hartono W. Compression tests of stainless steel tubular members. Journal of Structural Engineering (ASCE), 2002;128(6):754-61.

[5] Kuwamura H. Local buckling of thin-walled stainless steel members. Steel Structures, $2003 ; 3: 191-201$.

[6] Gardner L, Nethercot DA. Experiments on stainless steel hollow sections - Part 1: Material and cross-sectional behaviour. Journal of Constructional Steel Research, 2004;60(9):1291-318.

[7] Bardi FC, Kyriakides S. Plastic buckling of circular tubes under axial compression - part I: Experiments. International Journal of Mechanical Sciences, 2006;48(8):830-41.

[8] Paquette JA, Kyriakides S. Plastic buckling of tubes under axial compression and internal pressure. International Journal of Mechanical Sciences, 2006;48(8):855-67. 
[9] Lam D, Gardner L. Structural design of stainless steel concrete filled columns. Journal of Constructional Steel Research, 2008;64(11):1275-82.

[10] Uy B, Tao Z, Han LH. Behaviour of short and slender concrete-filled stainless steel tubular columns. Journal of Constructional Steel Research, 2011;67(3):360-78.

[11] Rasmussen KJR, Hancock GJ. Design of cold-formed stainless steel tubular members. II: Beams. Journal of Structural Engineering (ASCE), 1993;119(8):2368-86.

[12] Kiymaz G. Strength and stability criteria for thin-walled stainless steel circular hollow section members under bending. Thin-Walled Structures, 2005;43(10):1534-49.

[13] Zhao O, Gardner L, Young B. Structural performance of stainless steel circular hollow sections under combined axial load and bending - Part 1: Experiments and numerical modelling. Thin-Walled Structures, accepted.

[14] Buchanan C, Gardner L, Liew A. The continuous strength method for circular hollow sections. Proceedings of the 15th International Symposium on Tubular Structures, Rio de Janeiro, Brazil; 27-29 May 2015.

[15] Zhao O, Gardner L, Young B. Structural performance of stainless steel circular hollow sections under combined axial load and bending - Part 2: parametric studies and design. Thin-Walled Structures, accepted.

[16] Ashraf M, Gardner L, Nethercot DA. Compression strength of stainless steel crosssections. Journal of Constructional Steel Research, 2006;62(1):105-15. 
[17] Ashraf M, Gardner L, Nethercot DA. Resistance of stainless steel CHS columns based on cross-section deformation capacity. Journal of Constructional Steel Research, 2008;64(9):962-70.

[18] Ashraf M, Gardner L, Nethercot DA. Structural stainless steel design: resistance based on deformation capacity. Journal of Structural Engineering (ASCE), 2008;134(3):402-11.

[19] Gardner L. The Continuous Strength Method. Proceedings of the Institution of Civil Engineers - Structures and Buildings, 2008;161(3):127-33.

[20] Afshan S, Gardner L. The continuous strength method for structural stainless steel design. Thin-Walled Structures, 2013;68(4):42-49.

[21] Gardner L, Law KH, Buchanan C. Unified slenderness limits for structural steel circular hollow sections. Romanian Journal of Technical Sciences, Applied Mechanics, 2014;59(12):153-63.

[22] EN 1993-1-4. Eurocode 3: Design of steel structures - Part 1.4: General rules Supplementary rules for stainless steels. Brussels: European Committee for Standardization (CEN); 2006.

[23] SEI/ASCE 8-02. Specification for the design of cold-formed stainless steel structural members. Reston: American Society of Civil Engineers (ASCE); 2002.

[24] AS/NZS 4673. Cold-formed stainless steel structures. Sydney: AS/NZS 4673:2001; 2001

[25] Greiner R, Kettler M. Interaction of bending and axial compression of stainless steel members. Journal of Constructional Steel Research, 2008;64(11):1217-24. 
[26] Ramberg W, Osgood WR. Description of stress-strain curves by three parameters. Technical note No 902, Washington DC: National advisory committee for aeronautics; 1943.

[27] Hill HN. Determination of stress-strain relations from offset yield strength values. Technical note No 927, Washington DC: National advisory committee for aeronautics; 1944.

[28] Mirambell E, Real E. On the calculation of deflections in structural stainless steel beams: An experimental and numerical investigation. Journal of Constructional Steel Research, 2000;54(1):109-33.

[29] Rasmussen KJR. Full-range stress-strain curves for stainless steel alloys. Journal of Constructional Steel Research, 2003;59(1):47-61.

[30] Gardner L, Ashraf M. Structural design for non-linear metallic materials. Engineering Structures, 2006;28(6):926-34.

[31] Huang Y, Young B. Experimental investigation of cold-formed lean duplex stainless steel beam-columns. Thin-Walled Structures, 2014;76:105-17.

[32] Zhao O, Rossi B, Gardner L, Young, B. Behaviour of structural stainless steel crosssections under combined loading - Part I: Experimental study. Engineering Structures, $2015 ; 89: 236-46$.

[33] Law KH, Gardner L. Buckling of elliptical hollow section members under combined compression and uniaxial bending. Journal of Constructional Steel Research, 2013;86:1-16.

[34] Hibbitt, Karlsson \& Sorensen, Inc. ABAQUS. ABAQUS/Standard user's manual volumes I-III and ABAQUS CAE manual. Version 6.12. Pawtucket (USA); 2012. 
[35] Gardner L, Nethercot DA. Numerical modeling of stainless steel structural components A consistent approach. Journal of Structural Engineering (ASCE), 2004;130(10):1586-601.

[36] Ashraf M, Gardner L, Nethercot DA. Finite element modelling of structural stainless steel cross-sections. Thin-Walled Structures, 2006;44(10):1048-62.

[37] Becque J, Lecce M, Rasmussen KJR. The direct strength method for stainless steel compression members. Journal of Constructional Steel Research, 2008;64(11):1231-8.

[38] Theofanous M, Chan TM, Gardner L. Structural response of stainless steel oval hollow section compression members. Engineering Structures, 2009;31(4):922-34.

[39] Theofanous M, Gardner L. Testing and numerical modelling of lean duplex stainless steel hollow section columns. Engineering Structures, 2009;31(12):3047-58.

[40] Zhao O, Rossi B, Gardner L, Young B. Behaviour of structural stainless steel crosssections under combined loading - Part II: Numerical modelling and design approach. Engineering Structures, 2015;89:247-59.

[41] Huang Y, Young B. Design of cold-formed lean duplex stainless steel members in compression and bending. Journal of Structural Engineering (ASCE), 10.1061/(ASCE)ST. 1943-541X.0001091, 04014138.

[42] Zhao O, Rossi B, Gardner L, Young B. Experimental and numerical studies of ferritic stainless steel tubular cross-sections under combined compression and bending. Journal of Structural Engineering (ASCE), 10.1061/(ASCE)ST.1943-541X.0001366, 04015110. 
[43] Rasmussen KJR, Hancock GJ. Design of cold-formed stainless steel tubular members. I: Columns. Journal of Structural Engineering (ASCE), 1993;119(8):2349-67.

[44] Cruise RB, Gardner L. Residual stress analysis of structural stainless steel sections. Journal of Constructional Steel Research, 2008;64(3):352-66.

[45] Jandera M, Gardner L, Machacek J. Residual stresses in cold-rolled stainless steel hollow sections. Journal of Constructional Steel Research, 2008;64(11):1255-63.

[46] Teng JG, Rotter JM. (Eds.). Buckling of thin metal shells. CRC Press, 2006.

[47] Zhao O, Gardner L, Young B. Buckling of ferritic stainless steel members under combined axial compression and bending, Journal of Constructional Steel Research, $2016 ; 117: 35-48$

[48] EN 1993-1-1. Eurocode 3: Design of steel structures - Part 1.1: General rules and rules for buildings. Brussels: European Committee for Standardization (CEN); 2005.

[49] Rasmussen KJR, Rondal J. Strength curves for metal columns. Journal of Structural Engineering (ASCE), 1997;123(6):721-8. 


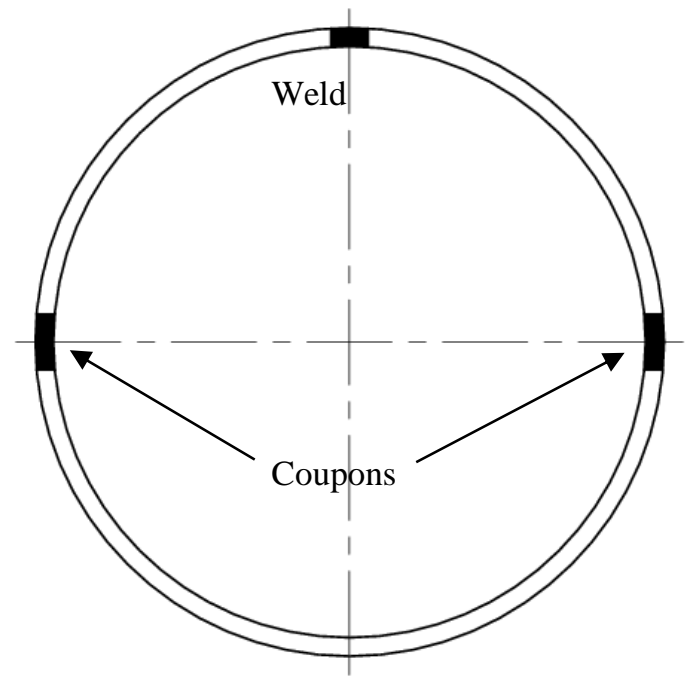

Fig. 1. Locations of tensile coupons in the cross-section.
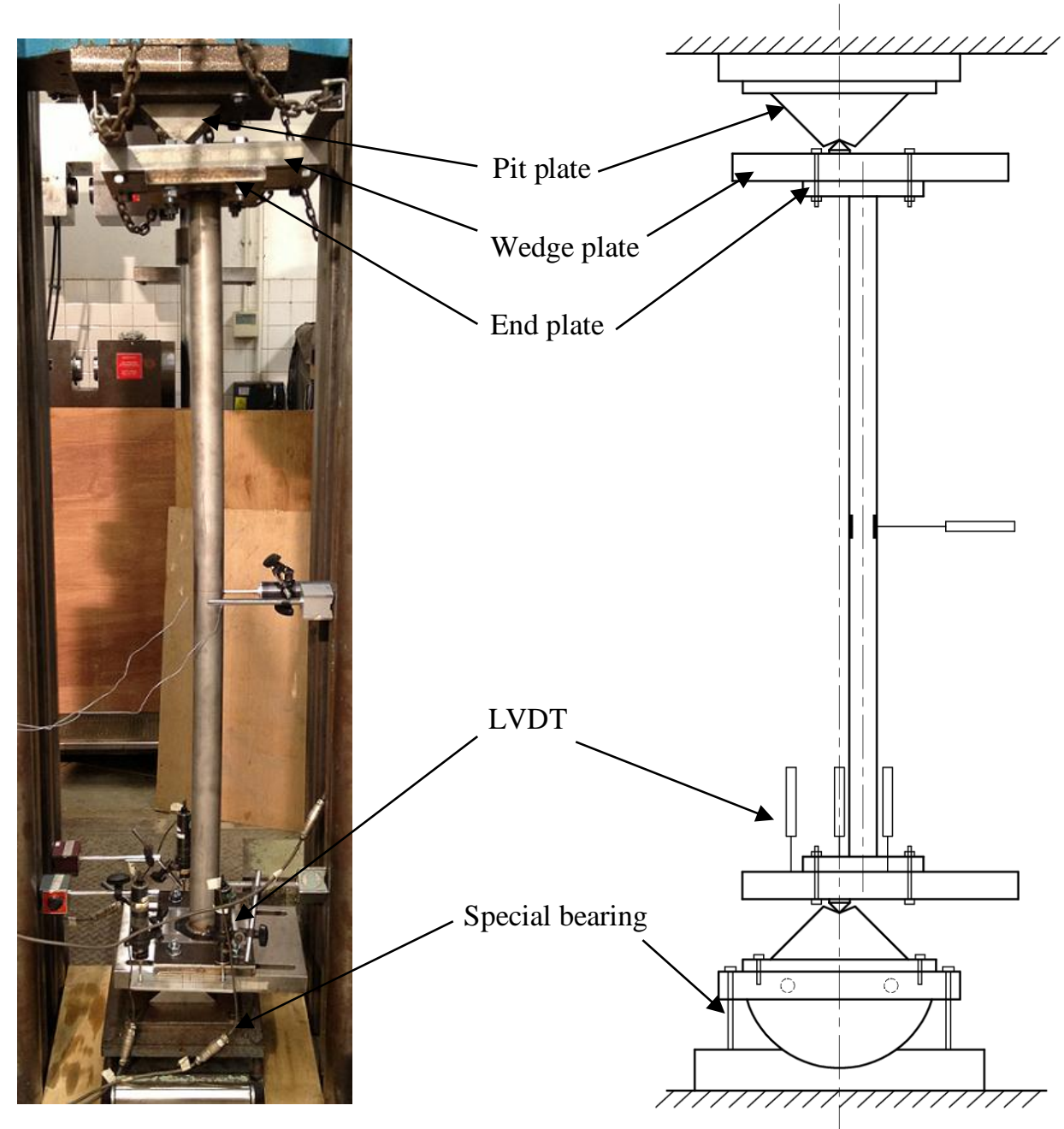

(a) Experimental setup.

(b) Schematic diagram of the test setup.

Fig. 2. Beam-column test configuration. 


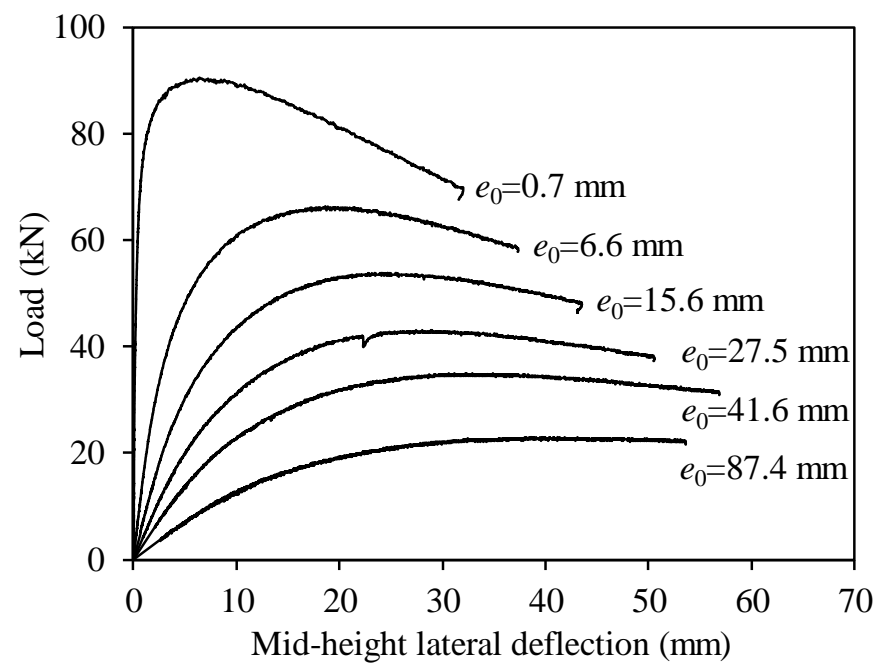

Fig. 3. Load-mid-height lateral deflection curves for beam-column tests on CHS $60.5 \times 2.8$ specimens.

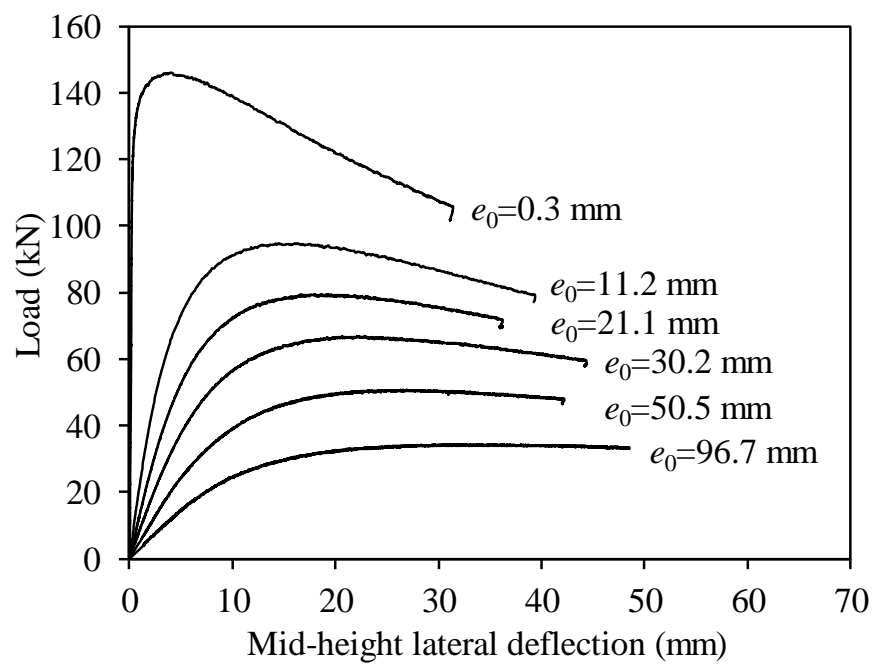

Fig. 4. Load-mid-height lateral deflection curves for beam-column tests on CHS $76.3 \times 3$ specimens. 


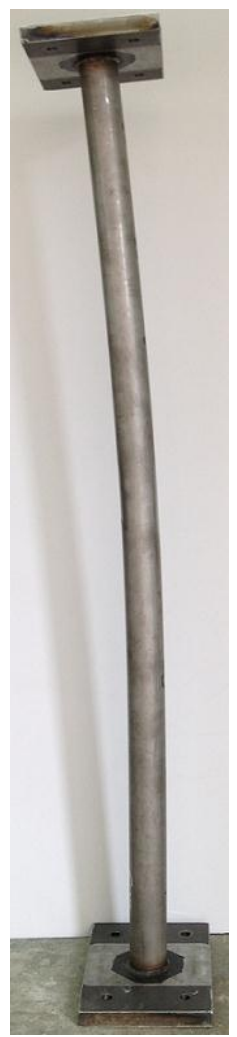

Fig. 5. Experimental and numerical failure modes for beam-column specimen CHS $60.5 \times 2.8-1 \mathrm{C}$.
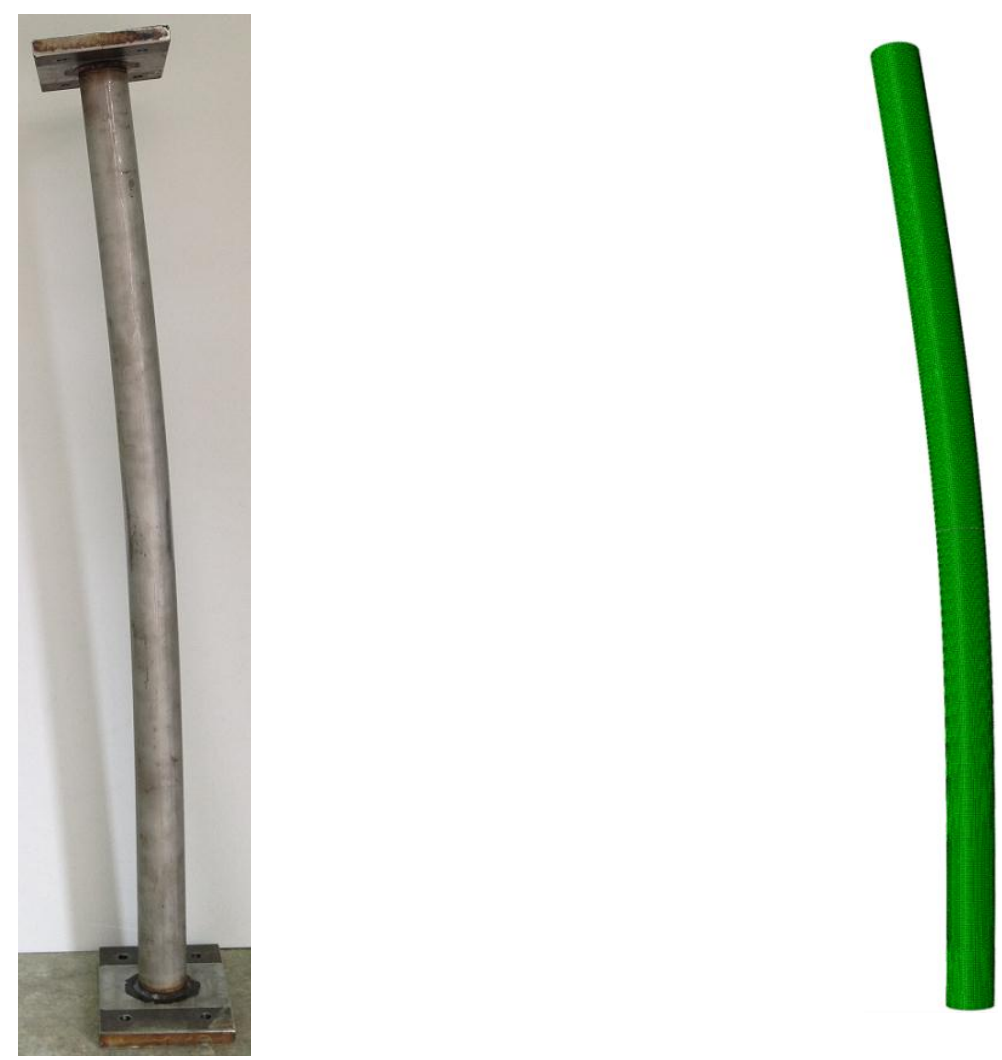

Fig. 6. Experimental and numerical failure modes for beam-column specimen CHS $76.3 \times 3-2 \mathrm{C}$. 


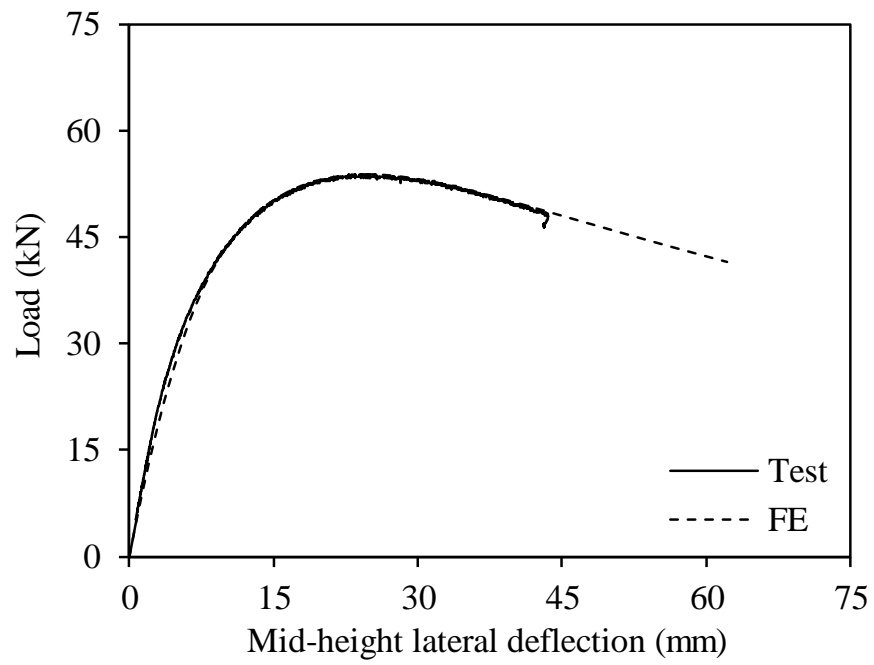

Fig. 7. Experimental and numerical load-mid-height lateral deflection curves for beam-column specimen CHS $60.5 \times 2.8-1 \mathrm{C}$.

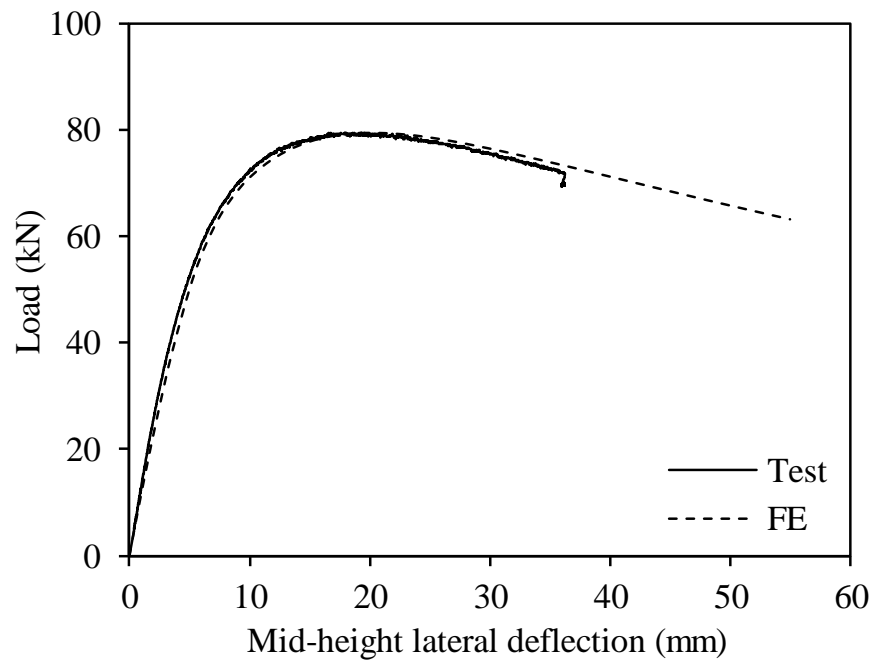

Fig. 8. Experimental and numerical load-mid-height lateral deflection curves for beam-column specimen CHS $76.3 \times 3-2 \mathrm{C}$. 


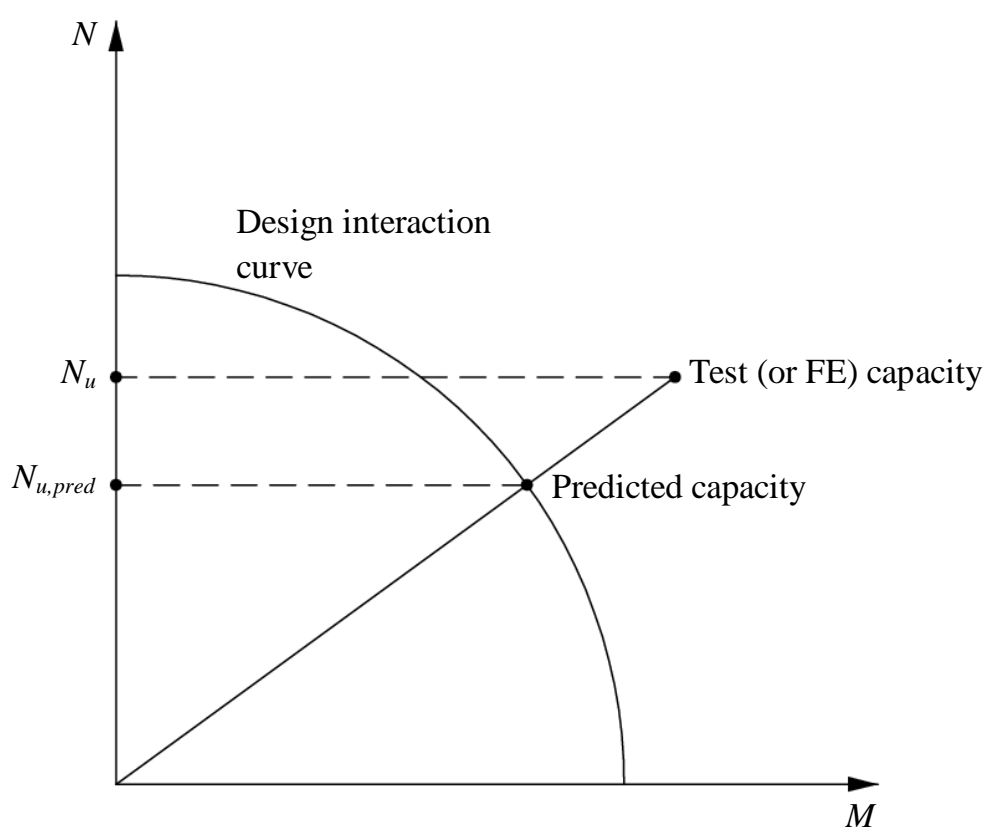

Fig. 9. Definition of $N_{u}$ and $N_{u \text {,pred }}$ on axial load--moment interaction curve.

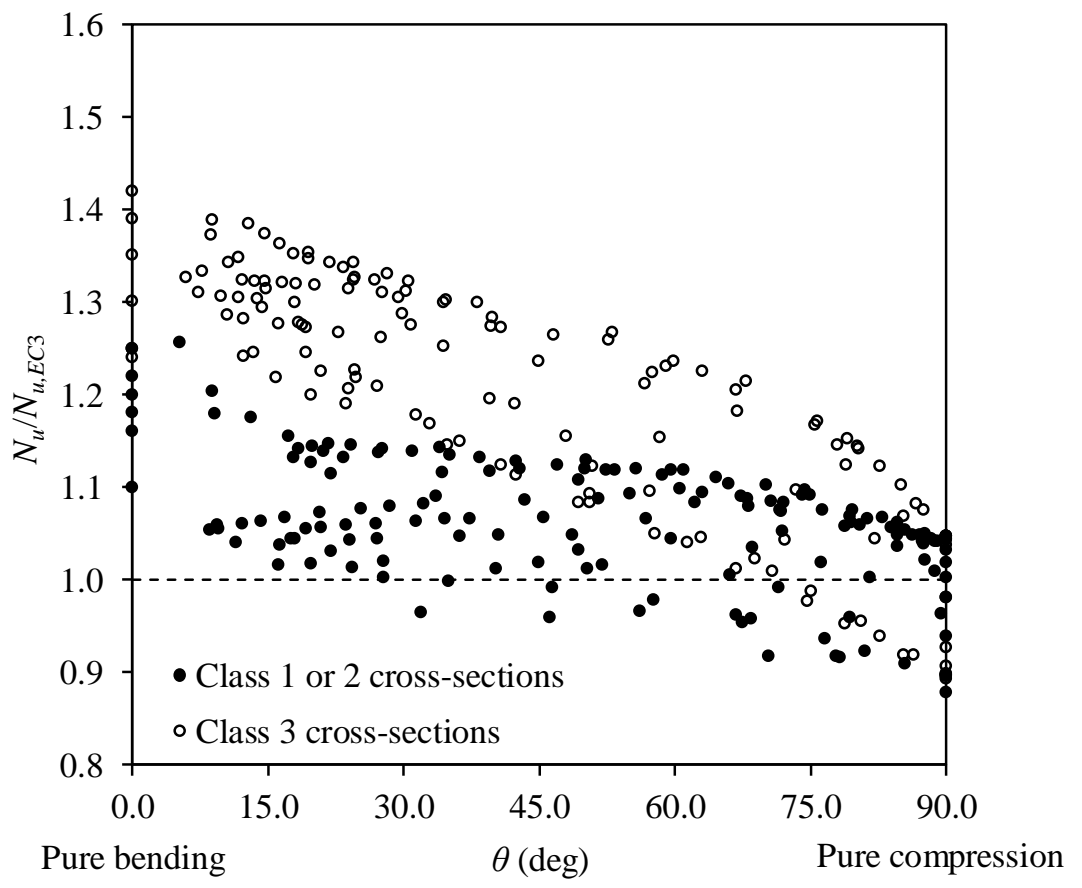

Fig. 10. Comparison of beam-column test and FE results with EC3 strength predictions. 


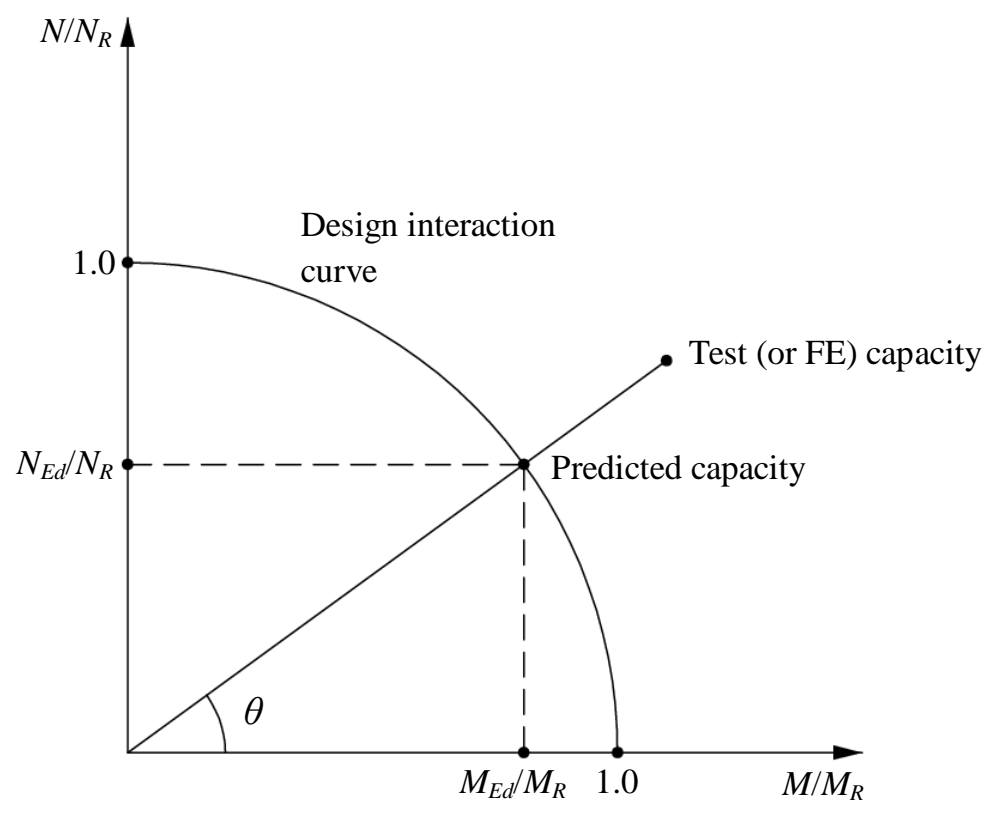

Fig. 11. Definition of $\theta$ on axial load-moment interaction curve.

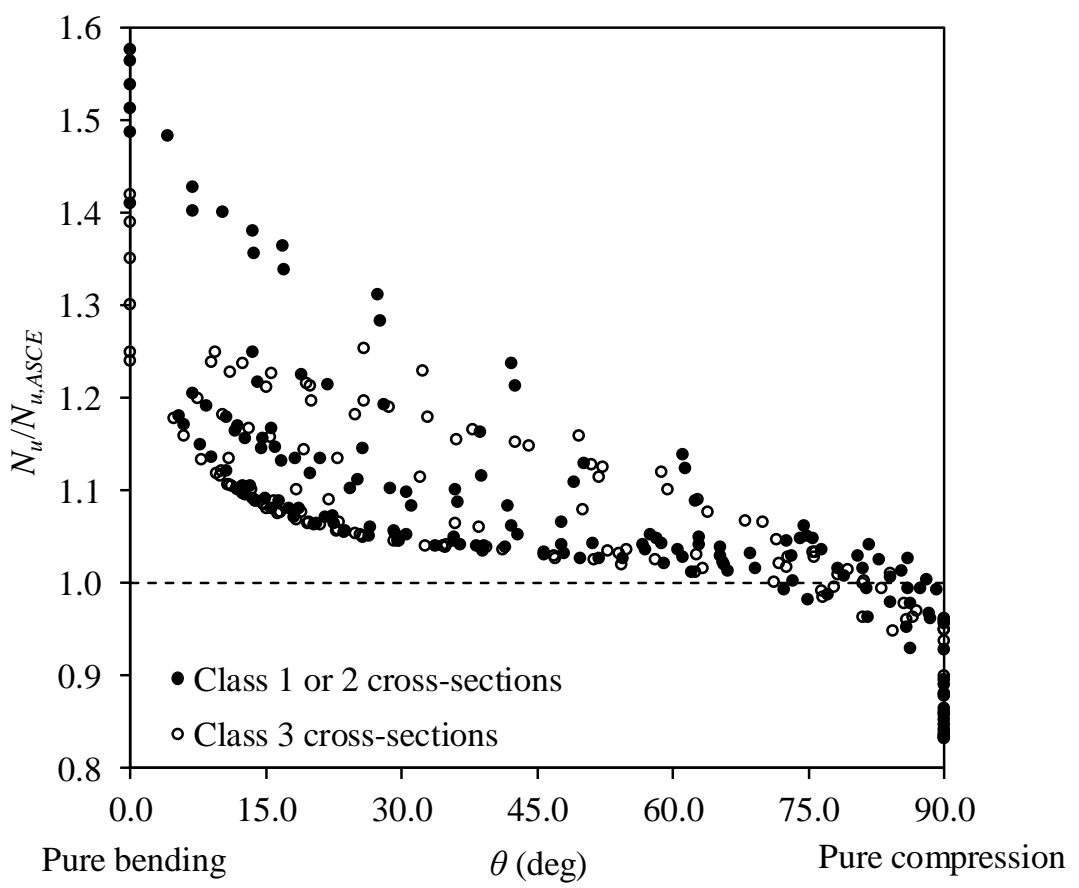

Fig. 12. Comparison of beam-column test and FE results with SEI/ASCE-8 strength predictions. 


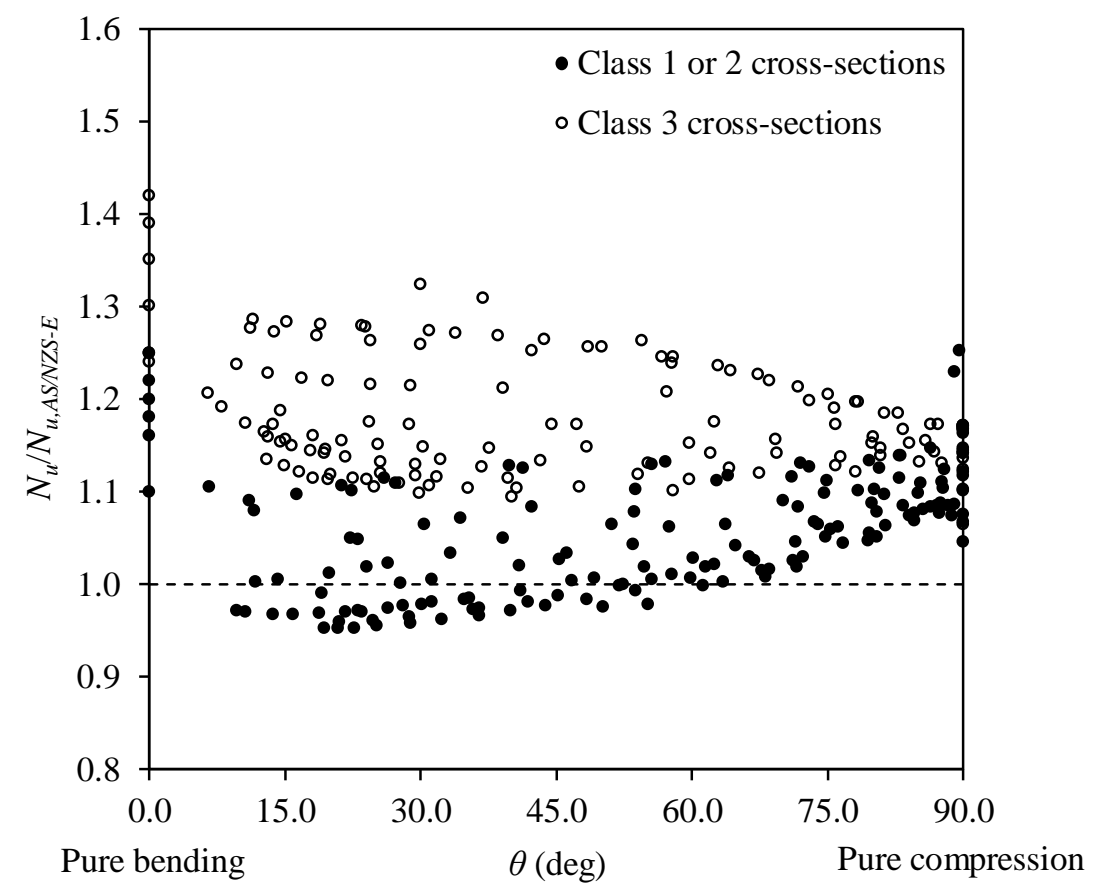

Fig. 13. Comparison of beam-column test and FE results with AS/NZS 4673 strength predictions. Note that $N_{u} / N_{u, A S N Z S-E}$ indicates that the explicit method is used to calculate the column buckling resistance.

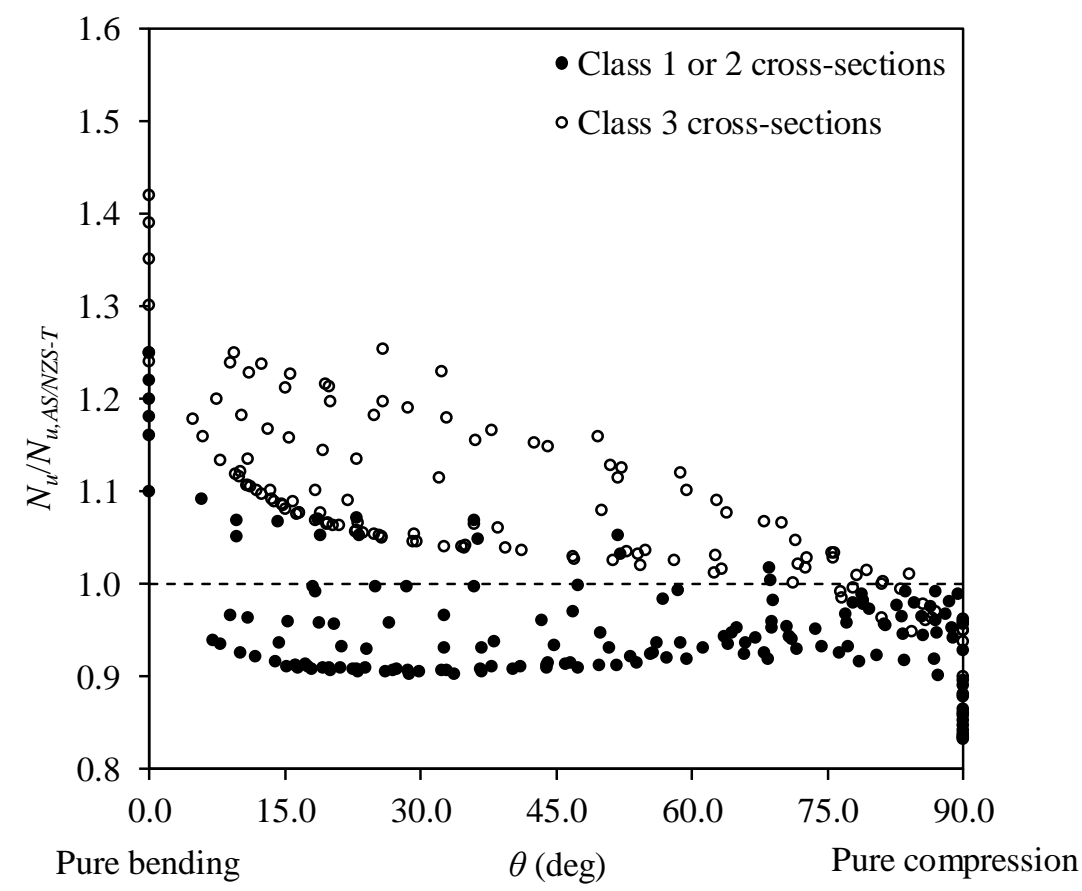

Fig. 14. Comparison of beam-column test and FE results with AS/NZS 4673 strength predictions. Note that $N_{u} / N_{u, A S N Z S-T}$ indicates that the tangent modulus approach is used to calculate the column buckling resistance. 


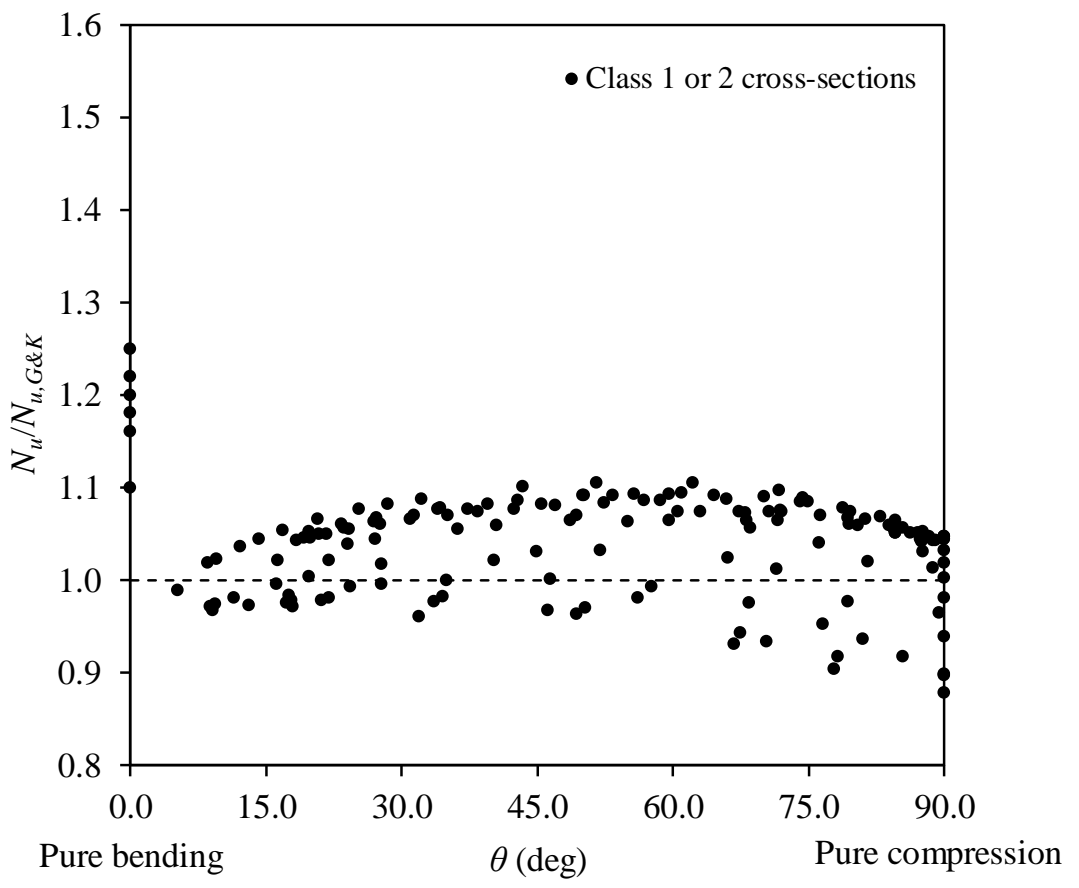

Fig. 15. Comparison of beam-column test and FE results with strength predictions of Greiner and Kettler, which applies to Class 1 and Class 2 cross-sections only. 


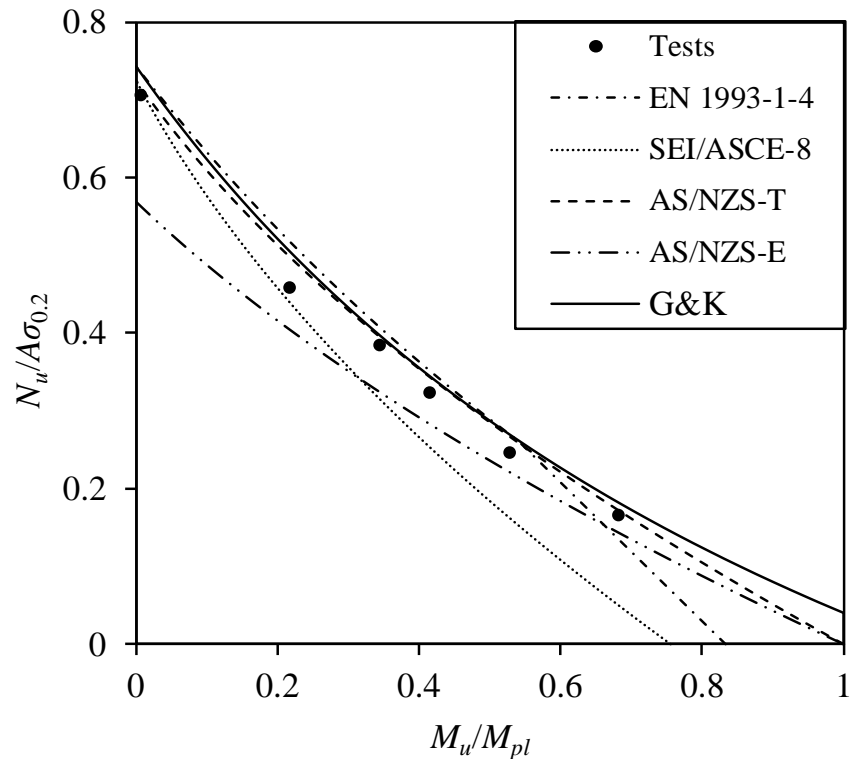

Fig. 16. Comparison of CHS $60.5 \times 2.8$ beam-column test results with five design interaction curves.

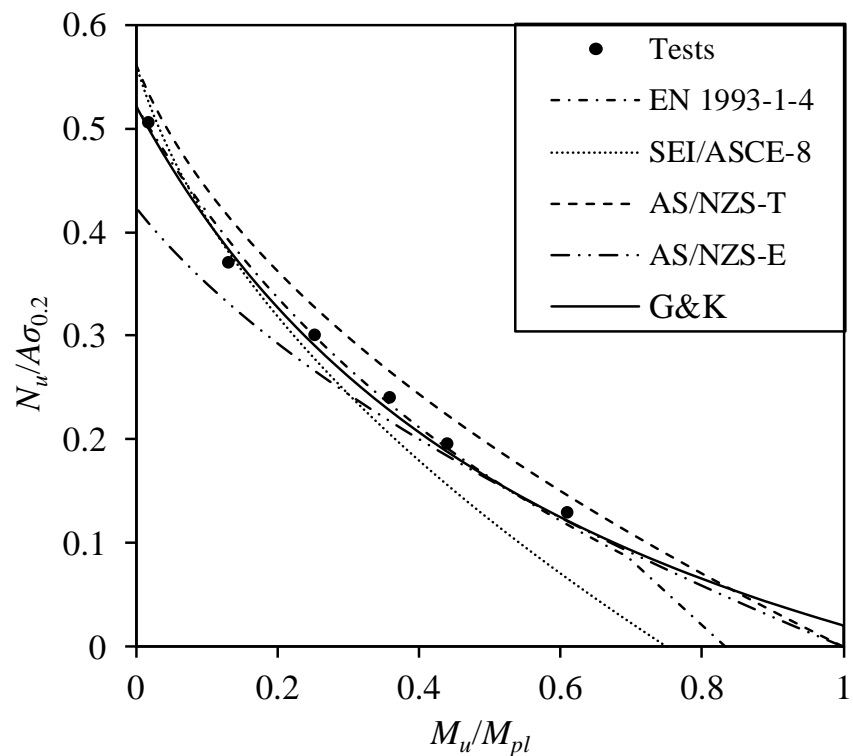

Fig. 17. Comparison of CHS $76.3 \times 3$ beam-column test results with five design interaction curves. 
Table 1 Summary of key measured material properties from the tensile coupons.

\begin{tabular}{lccccccccc}
\hline Cross-section & $E$ & $\sigma_{0.2}$ & $\sigma_{1.0}$ & $\sigma_{u}$ & $\varepsilon_{u}$ & $\varepsilon_{f}$ & \multicolumn{3}{c}{ R-O coefficient } \\
\cline { 8 - 12 } & $(\mathrm{GPa})$ & $(\mathrm{MPa})$ & $(\mathrm{MPa})$ & $(\mathrm{MPa})$ & $(\%)$ & $(\%)$ & $n$ & $n_{0.2,1.0}^{\prime}$ & $n_{0.2, u}^{\prime}$ \\
\hline CHS 60.5×2.8 & 190 & 355 & 396 & 780 & 47 & 55 & 5.3 & 2.4 & 1.9 \\
CHS 76.3×3 & 195 & 302 & 347 & 784 & 48 & 56 & 7.3 & 2.0 & 1.9 \\
\hline
\end{tabular}

Table 2 Measured geometric properties of beam-column specimens.

\begin{tabular}{lcccccccc}
\hline Cross-section & Specimen ID & $\bar{\lambda}$ & $\begin{array}{c}L \\
(\mathrm{~mm})\end{array}$ & $\begin{array}{c}L_{e} \\
(\mathrm{~mm})\end{array}$ & $\begin{array}{c}D \\
(\mathrm{~mm})\end{array}$ & $\begin{array}{c}t \\
(\mathrm{~mm})\end{array}$ & $\begin{array}{c}A \\
\left(\mathrm{~mm}^{2}\right)\end{array}$ & $\begin{array}{c}\omega_{g} \\
(\mathrm{~mm})\end{array}$ \\
\hline \multirow{5}{*}{ CHS 60.5×2.8 } & 1A & 1.10 & 1450 & 1624.8 & 60.40 & 2.78 & 503.23 & 0.38 \\
& 1B & 1.10 & 1450 & 1624.8 & 60.40 & 2.78 & 503.23 & 0.51 \\
& 1C & 1.10 & 1450 & 1624.8 & 60.36 & 2.78 & 502.88 & 0.25 \\
& 1D & 1.10 & 1450 & 1624.8 & 60.42 & 2.79 & 505.13 & 0.38 \\
& 1E & 1.10 & 1450 & 1624.8 & 60.46 & 2.80 & 507.20 & 0.64 \\
1F & 1.10 & 1450 & 1624.8 & 60.40 & 2.79 & 504.95 & 1.02 \\
\hline & 2A & 0.78 & 1450 & 1624.8 & 76.40 & 3.00 & 691.78 & 0.38 \\
& 2B & 0.78 & 1450 & 1624.8 & 76.36 & 2.96 & 682.55 & 0.38 \\
& 2C & 0.78 & 1450 & 1624.8 & 76.34 & 2.99 & 689.00 & 0.51 \\
& 2D & 0.78 & 1450 & 1624.8 & 76.32 & 2.97 & 684.39 & 0.51 \\
& 2E & 0.78 & 1450 & 1624.8 & 76.40 & 2.99 & 689.57 & 0.64 \\
& 2F & 0.78 & 1450 & 1624.8 & 76.35 & 2.98 & 686.89 & 0.51 \\
\hline
\end{tabular}


Table 3 Summary of CHS beam-column test results.

\begin{tabular}{ccccccccc}
\hline Cross-section & Specimen ID & $\begin{array}{c}e_{n} \\
(\mathrm{~mm})\end{array}$ & $\begin{array}{c}e_{0} \\
(\mathrm{~mm})\end{array}$ & $\begin{array}{c}N_{u} \\
(\mathrm{kN})\end{array}$ & $\begin{array}{c}\delta_{u} \\
(\mathrm{~mm})\end{array}$ & $\begin{array}{c}M_{1 s t, e l, u} \\
(\mathrm{kNm})\end{array}$ & $\begin{array}{c}M_{2 \text { nd,el, } u} \\
(\mathrm{kNm})\end{array}$ & $\begin{array}{c}M_{2 \text { nd,inel, } u} \\
(\mathrm{kNm})\end{array}$ \\
\hline \multirow{5}{*}{ CHS 60.5×2.8 } & 1A & 0.0 & 0.7 & 90.5 & 6.4 & 0.10 & 0.25 & 0.68 \\
& 1B & 5.0 & 6.6 & 66.3 & 18.9 & 0.47 & 0.85 & 1.72 \\
& 1C & 15.0 & 15.6 & 53.8 & 25.7 & 0.85 & 1.34 & 2.24 \\
& 1D & 25.0 & 27.5 & 43.1 & 29.0 & 1.20 & 1.69 & 2.45 \\
& 1E & 40.0 & 41.6 & 35.0 & 34.9 & 1.48 & 1.93 & 2.70 \\
& 1F & 85.0 & 87.4 & 23.0 & 43.1 & 2.03 & 2.41 & 3.02 \\
\hline & 2A & 0.0 & 0.3 & 146.0 & 4.1 & 0.10 & 0.17 & 0.70 \\
& 2B & 10.0 & 11.2 & 94.7 & 16.4 & 1.10 & 1.53 & 2.65 \\
& 2C & 20.0 & 21.1 & 79.4 & 19.6 & 1.72 & 2.24 & 3.27 \\
& 2D & 30.0 & 30.2 & 66.9 & 22.9 & 2.05 & 2.57 & 3.59 \\
& 2E & 50.0 & 50.5 & 50.8 & 26.6 & 2.60 & 3.06 & 3.95 \\
& 2F & 95.0 & 96.7 & 34.3 & 38.7 & 3.33 & 3.71 & 4.66 \\
\hline
\end{tabular}

Table 4 Comparison of beam-column test results with FE results for varying imperfection levels.

\begin{tabular}{|c|c|c|c|c|c|c|c|}
\hline \multirow[t]{2}{*}{ Cross-section } & \multirow[t]{2}{*}{ Specimen ID } & \multicolumn{6}{|c|}{ FE $N_{u} /$ Test $N_{u}$} \\
\hline & & $\omega_{g}+t / 100$ & $L / 1000+t / 100$ & $L / 1500+t / 100$ & $\omega_{g}+t / 10$ & $L / 1000+t / 10$ & $L / 1500+t / 10$ \\
\hline \multirow{6}{*}{ CHS $60.5 \times 2.8$} & $1 \mathrm{~A}$ & 1.011 & 0.946 & 0.968 & 1.011 & 0.946 & 0.968 \\
\hline & $1 \mathrm{~B}$ & 1.050 & 1.025 & 1.037 & 1.050 & 1.025 & 1.037 \\
\hline & $1 \mathrm{C}$ & 1.026 & 1.008 & 1.017 & 1.018 & 1.000 & 1.009 \\
\hline & 1D & 1.022 & 1.009 & 1.015 & 1.015 & 1.001 & 1.008 \\
\hline & $1 \mathrm{E}$ & 1.026 & 1.014 & 1.020 & 1.019 & 1.008 & 1.013 \\
\hline & $1 \mathrm{~F}$ & 1.000 & 0.993 & 0.996 & 0.993 & 0.986 & 0.989 \\
\hline \multirow{6}{*}{ CHS $76.3 \times 3$} & $2 \mathrm{~A}$ & 0.991 & 0.938 & 0.958 & 0.991 & 0.938 & 0.958 \\
\hline & $2 \mathrm{~B}$ & 1.049 & 1.030 & 1.039 & 1.049 & 1.030 & 1.039 \\
\hline & $2 \mathrm{C}$ & 1.022 & 1.007 & 1.014 & 1.015 & 1.000 & 1.007 \\
\hline & $2 \mathrm{D}$ & 1.041 & 1.028 & 1.035 & 1.039 & 1.026 & 1.033 \\
\hline & $2 \mathrm{E}$ & 1.045 & 1.035 & 1.040 & 1.038 & 1.028 & 1.033 \\
\hline & $2 \mathrm{~F}$ & 1.011 & 1.005 & 1.008 & 1.005 & 0.999 & 1.002 \\
\hline \multicolumn{2}{|c|}{ Mean } & 1.024 & 1.003 & 1.012 & 1.020 & 0.999 & 1.008 \\
\hline \multicolumn{2}{|c|}{$\mathrm{COV}$} & 0.019 & 0.031 & 0.026 & 0.020 & 0.030 & 0.026 \\
\hline
\end{tabular}


Table 5 Comparison of beam-column test and FE results with predicted strengths for Class 1 or 2 cross-sections.

\begin{tabular}{cccccc}
\hline $\begin{array}{c}\text { No. of tests: } 12 \\
\text { No. of FE simulations: } 150\end{array}$ & $N_{u} / N_{u, E C 3}$ & $N_{u} / N_{u, A S C E}$ & $N_{u} / N_{u, A S / N Z S-E}$ & $N_{u} / N_{u, A S / N Z S-T}$ & $N_{u} / N_{u, G \& K}$ \\
\hline Mean & 1.06 & 1.09 & 1.06 & 0.95 & 1.04 \\
COV & 0.06 & 0.13 & 0.06 & 0.07 & 0.06 \\
\hline
\end{tabular}

Table 6 Comparison of beam-column test and FE results with predicted strengths for Class 3 cross-sections.

\begin{tabular}{ccccc}
\hline $\begin{array}{c}\text { No. of tests: } 0 \\
\text { No. of FE simulations: } 135\end{array}$ & $N_{u} / N_{u, E C 3}$ & $N_{u} / N_{u, A S C E}$ & $N_{u} / N_{u, A S / N Z S-E}$ & $N_{u} / N_{u, A S / N Z S-T}$ \\
\hline Mean & 1.20 & 1.08 & 1.18 & 1.08 \\
COV & 0.11 & 0.10 & 0.06 & 0.10 \\
\hline
\end{tabular}

